\title{
A Qualitative Analysis of the Nature and Causes of Truancy Among the University Students in Tripoli, Lebanon
}

\author{
Maya Bazhouni, PhD \\ Lebanese University, Lebanon
}

Doi:10.19044/esj.2019.v15n31p168 URL:http://dx.doi.org/10.19044/esj.2019.v15n31p168

\begin{abstract}
Class attendance and involvement in school activities are essential for academic achievement. Nonetheless, truancy, chronic absenteeism, or skipping more than $20 \%$ of lectures per semester, is a major problem globally. Numerous investigations have focused on the prevalence and impacts of truancy, but none have been conducted in Lebanon. Therefore, the purpose of the present research was to fill the gap in the literature and explore the nature and causes of truant behaviors among students in two universities in Tripoli, Lebanon. The study espoused a qualitative descriptive design, which entailed face-to-face semi-structured interviews with ten purposefully sampled respondents. The gathered data was analyzed thematically, leading to the identification of two major themes and four sub-themes. Notably, family dynamics, the instructional techniques and lecture content, and the student qualities, particularly conscientiousness, influenced the decision to attend or skip classes. The sampled students concurred that there was a need for training professors to diversify their teaching approaches, and subsequently, reduce boredom and truancy.
\end{abstract}

Keywords: Truancy, Class Non-Attendance, Skipping, Academic Achievement, Students

\section{Introduction}

Lecture attendance and class participation play essential roles in contemporary higher education. Numerous past studies have identified class attendance as a significant predictor of learning outcomes, with students who skip several classes scoring poorly in their final exams compared to regular attendees (Lukkarinen, Koivukangas, \& Seppälä, 2016; Moore, Jensen, Hatch, Duranczyk, \& Staats, 2003). Purcell (2007) conducted a quantitative study to ascertain the influence of class attendance on exam performance among engineering students at the University of Dublin, Ireland. The outcomes showed that only $68 \%$ of the upcoming engineers regularly appeared in 
lectures, and most of those who failed their final tests were among the $32 \%$ of chronic absentees. Besides, Purcell (2007) further observed that for every $10 \%$ increase in class turnout, there was an average of $3 \%$ improvement in exam performance. Kirby and McElroy (2003) investigated the correlation between lecture attendance and grade among first-year economic students at the University of Cork. Comparable to Purcell (2007) findings, only 66\% of students frequently turned up for lectures at the University College of Cork. Kirby and McElroy (2003) also noted a positive connection between school attendance and exam scores.

Existing pieces of literature confirm the significance of lectures in knowledge acquisition. Lectures entail the transmission of information from a tutor to the student in an interactional approach. As per Bati, Mandiracioglu, Orgun, and Govsa (2013), it is the primary instructing technique in postsecondary education as well as the most productive and economical method of transferring knowledge. Guleker (2014) adds that lectures allow professors to introduce a complex subject or demonstrate the application of theoretical concepts in real-life scenarios. They support reflection on a topic, facilitate comprehension, and allow apprentices to develop scientific thoughts about a subject (Lukkarinen et al., 2016; Cantillon, 2003). Moreover, through physical interactions in lectures, tutors can provide direction with suggestions as to how a certain procedure or subject can be learned; thereby, nurturing the development of independent thinking among students with respect to their professions.

Nonetheless, recent studies have reported varying findings regarding the positive effect of lecture attendance on student outcomes. For example, Cortright, Lujan, Cox, and DiCarlo (2011) engaged $n=51$ undergraduate students pursuing a physiology course in a comparative investigation to explore the disparity of influence of lecture attendance on exam grades between male and female apprentices. The authors noted that the impact of regular lecture attendance on examination scores was more marked in the female than in male students. In another research, Eisen et al. (2015) surveyed $\mathrm{n}=101$ second-year medical students taking an introductory dermatology unit to determine the influences of attending lectures and learning choices on their performance in the course. The findings reported no statistically significant correlation between the studied variables. Those students who preferred watching academic online videos over class attendances performed better in the dermatology course. Regardless, their tutors highlighted the value of lectures in demonstration of pragmatic clinical cases.

Despite the emphasis of lecture attendance by numerous scholars, chronic absenteeism or truancy, which is defined as the unexcused or excused school non-attendance for more than ten days in an academic year, is a major problem in institutions of higher learning globally (Bati et al., 2013; Epstein \& Sheldon, 
2002; Jacob \& Lovett, 2017). As described earlier, the study by Purcell (2007) showed that, on average, $32 \%$ of students missed classes in Ireland, while in Finland, $60 \%$ of civil engineering students skived classes (Kolari, SavanderRanne, \& Viskari 2008). In the United States, it is projected that $14 \%$ and $16 \%$, corresponding to 6.125 million and 7 million students, skipped classes without permission during the 2013-2014 and 2015-2016 academic years, respectively (Jacob \& Lovett, 2017; U.S. Department of Education, 2017). The average absenteeism rate in Dey (2018) paper published in the U.S. was $27 \%$, while a recent study conducted in Ireland reported a $20 \%$ prevalence of lecture non-attendance among pharmacy students at Ulster University (Irwin, Burnett, \& McCarron, 2018). At Hawassa University, Ethiopia, Desalegn, Berhan, and Berhan (2014) found that $14 . \%$ and $43.7 \%$ of 1,200 medical students who took part in the study missed more than eight and four lectures, respectively in the preceding semesters. A quantitative study that aimed at exploring the pervasiveness and predictors of school truancy in seven member states of the Association of Southeast Asian Nations (ASEAN) found that in six nations, the incidence rates of absenteeism varied between $20 \%$ in Myanmar and more than 30\% in Indonesia, Brunei Darussalam, and the Philippines (Pengpid \& Peltzer, 2017).

In Lebanon, available information suggests that truancy is a pervasive problem that undermines learners' education, and consequently, resulting in heightened dropout rates which eventually cause harm to the entire community (Nawal et al., 2012). This is in line with arguments in other studies showing that chronic absenteeism is associated with negative outcomes, including poor academic performance, premature withdrawal from school and the associated unemployment, extended time before graduation, and financial losses, especially for government-sponsored students (Pinchak, 2018; Snyder, LeePartridge, Jarmoszko, Petkova, \& D’Onofrio, 2014; Teixeira, 2016). Scholars have attributed the low rates of lecture attendance in post-secondary educations to various causes that ought to be brought to light.

According to Bati et al. (2013), the antecedents shaping truancy among students are generally discussed in terms of difficulty in adjusting to the campus atmosphere and low motivation levels. The predominant aspects that influence attendance encompass the preparedness of the instructor, mandatoriness of lectures, the quality of tutor-lecture-student interaction, availability and accessibility of learning resources, instruction modality, the scope and complexity of the course, time management, stress, work-related aspects, and travelling challenges, among others (Irwin et al., 2018; Landin \& Pérez, 2015; Delaney et al., 2013; Desalegn et al., 2014). Other studies have associated intrinsic and extrinsic motivators, like the wish to be successful, the capability to exploit academic resources, supportiveness and attitudes of professors, with increased lecture turnout (Moore et al., 2003; Crede, Roch, \& 
Kieszczynka, 2010). As per these authors, poor self-evaluation is among the most influential determiants of class attendance among university learners as it results in a decline in both interactions with instructors and educational performance.

Various solutions have been proposed to curb the rising rates of truancy in universities across the globe. For example, students surveyed in Desalegn et al. (2014) blamed the low rates of lecture non-attendance to the instructors' unpreparedness to teach making the class boring. Thus, tutors must master the course content and employ a myriad of teaching techniques that increase student participation and morale to appear in class. This may also entail involving students in deciding the preferred method of instructing as proposed by Alshammari (2016). Knoster (2016) recommends the espousal of data-driven approaches to identify, track, and support apprentices experiencing challenges in attending classes. Similar, while some schools emphasize the need for making lectures compulsory, others disagree. For example, whereas the mandatoriness of lectures appeared to be correlated with reduced absenteeism rates among medical students in Desalegn et al.'s (2014) study, it caused no significant difference in Snyder et al.'s (2014) investigation. Thus, there is a need for additional empirical investigations to identify the most potent approaches to reducing truancy rates among university students and the associated negative outcomes.

\section{Statement of Problem}

From the briefly appraised investigations, it is apparent lectures are among the most productive and economic approaches of teaching in postsecondary education. Thus, frequent attendance is straightforwardly associated with better academic accomplishments (Lukkarinen et al. 2016; Moore et al., 2003; Purcell, 2007). On the contrary, chronic absenteeism has been linked to poor student outcomes, including heightened risk for dropout, unemployment, lack of interaction with professors and students, low examination grades, failure to master essential concepts and techniques, particularly for medical students, and wastage of human and financial resources (Cortright et al., 2011; Lukkarinen et al 2016; Bati et al., 2013; Epstein \& Sheldon, 2002; Guleker, 2014). Irrespective of the above association, truancy remains a pervasive challenge in institutions of higher learning worldwide (Pengpid \& Peltzer, 2017; Eisen et al., 2015; Kolari et al., 2008; Purcell, 2007; Irwin et al., 2018; Dey, 2018; Desalegn et al., 2014; Eisen et al., 2015). Nonetheless, in addition to the fact that all the reviewed pieces of literature were not conducted in Lebanon, there is no published data on the extent, causes, impacts, or solutions proposed to address truancy in Lebanon, an issue that necessitates further investigation. 


\section{Study Objective}

The overall objective of the present qualitative investigation was to uncover the factors determining truancy among students attending the two Lebanese universities, namely: University of Tripoli and Manar University of Tripoli.

\section{Research Questions}

The study was guided by the following research questions:

1. Why do students at the University of Tripoli and Manar University of Tripoli skip classes?

2. What are the probable solutions to mitigate truancy at the University of Tripoli and Manar University of Tripoli?

\section{Research Design}

The research espoused a qualitative descriptive study framework to investigate the nature and drivers of truancy among university students in two universities in Tripoli, Lebanon. According to Grossoemme (2015), qualitative research is concerned with the nature or quality of human encounters and show the implication of life experiences to individuals. Qualitative studies are inclined to answer "how", "what", and "why" forms of research questions instead of "how many" or "how much", which are often resolved via quantitative techniques (Draper, 2005). In the current study, the goal was to uncover the detailed reasons and nature of truancy, and not how many university students skipped classes in the target universities, which underscored the adoption of the qualitative framework. Draper (2005) adds that most qualitative investigations are holistic and naturalistic as they pay attention to study participants in their natural environments, like the campus setting. From the reviewed literature, it is apparent that absenteeism is allied to a diversity of variables, including difficulty in adjusting to the campus environment, personality needs, and socioeconomic factors, among others. Thus, the application of qualitative descriptive framework has the prospect of generating new understandings on the nature and causes of truancy among university students in Tripoli.

\section{Setting and Respondents}

As outlined earlier, the investigation was conducted in two Lebanese universities, namely: University of Tripoli and Manar University of Tripoli. To ensure the selection of respondents was not biased, the maximum variation and criterion sampling techniques were employed. According to Palinkas et al. (2015), whereas criterion sampling involves identification and selection of all individuals satisfying a predetermined set of standards, maximum variation approach involves picking cases with shared patterns, especially from a 
heterogeneous population. Thus, the two selection tactics entail the purposeful sampling of a broad array of cases with diverse views with regards to the phenomenon under study. In Clores's (2009) standpoint, by choosing informants with heterogenous views and perceptions, investigators predict emerging or preconceived conceptualizations.

Since the target respondents were students with a history of truancy, those who had failed examinations owing to absenteeism (AF) were purposefully identified using the Summary Report on Student Absenteeism in the second semester of the 2018-2019 academic year that was obtained from the Registrars' offices of both universities. A total of 10 students aged between 18 and 41 years, who scored AF in either their minor or major courses or obtained a warning letter for not attending at least $80 \%$ of all lectures were requested to take part in the investigation. The sample included four males and six females, five had part-time employments, and six were married. The researcher also requested the email addresses of the target students from Academic Registrars' offices and sent them a request for interviews and a consent letter that detailed the objective, purpose, methodology, and the fate of the information. In the consent form, the researcher assured the respondents that their personal information would be kept anonymous through the use of pseudonyms to conceal their identities and that confidentiality will be maintained all through the investigation. Ten out of the twenty students (five from each university) agreed to participate in the study voluntarily.

\section{Data Collection and Analysis}

As outlined above, data was gathered through a semi-structured interview. According to Sekaran and Bougie (2016), semi-structured interviews are exhaustive consultations which allow participants to answer specific open-ended queries grounded on a preset interview guide. In the current study, the interview questions were predesigned to prompt a discussion that enabled the respondents to articulately describe their reasons for skipping classes, as well as their perceived solutions to enhance their class attendance. With the permission of the participants, each interview session was taped and later transcribed. This is in line with Jamshed's (2014) recommendation that recording of interviews is a suitable approach for capturing data more effectively compared to hand written notes only. Notably, taping of interviews enhances the reliability of the findings and heightens the researcher's concentration on the verbal prompts and the interview content, and therefore, aiding the transcriptionist to develop verbatim transcripts. Therefore, recording of the interviews and the use of an interview guide in the current study were the target techniques of guaranteeing reliability and trustworthiness of the findings. 


\section{Data Analysis}

The thematic analytic technique was used to analyze the interview transcribes. As outlined by Jugder (2016), thematic analysis is an approach that is utilized to isolate, analyze, and document common themes or patterns in interview transcripts. This method was chosen as it enabled the scholar to map out common themes representing the causes, impacts, and probable resolutions to mitigate truancy in two universities in Tripoli, Lebanon as shown in appendix B.

\section{Discussion of Results \\ Socio-Demographic Features of the Participants}

As shown in appendix A, out of the ten respondents who were interviewed, there were four males and six females. Six were married and $50 \%$ of all the respondents had part-time jobs. A snapshot of the number of hours skipped by the students showed that interviewees aged below twenty-years are less likely to miss eight or more classes in a semester, while individuals over twenty-two years are more likely to be truant for more than eight hours. This is supported by existing pieces of literature that have identified age of the students as a predictor of non-attendance. For instance, Desalegn et al. (2014) observed that university students older than twenty years represent an employed and married cohort, and therefore, they often face challenges in balancing work, family, and school activities. The latter heightens their probability to miss classes with or without seeking consent. Nonetheless, in addition to age, seven key themes were identified as the common causes of skipping classes among the interviewees as discussed below.

\section{Causes of Truant Behaviors among University Students in Lebanon}

Family dynamics. From the interview responses, lecture non-attendance was associated with an array of family circumstances. For five of the interviewed

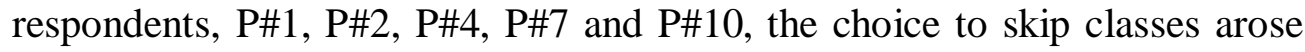
from disempowering experiences that are voiced as indications of helplessness against a number of basic pragmatic challenges in the family, safety, and health. For example, P\#7 and P\#4 expressed that they failed to show up for classes to attend to ailing family members.

P\#7 indicated that "I missed school for three days when my grandmother underwent surgery and had to be hospitalized. She was old, about 80 years. She had cancer of the throat. Unfortunately, she did not make out alive so the funeral plans forced me to skip class for another week. My parents are deceased, so I felt responsible for everything."

Similarly, P\#4 reiterated that "there was no way I could come to class while my mother was fighting for her life in hospital. Since I come from a 
single-parent family, we had to take shifts with my younger sister to watch over our mom."

P\#2 and P\#10 are drawn from low-income families, where parents are remarkably busy, working long hours to care for their families, thereby having no time to supervise or monitor their children behaviors. In P\#2's standpoint, "missing classes has been my weak point since high school," while P\#10 indicated that, "my mom does not even know I skipped classes both in high school and now. She is too busy to notice." These responses are in line with the findings of Marsh's (2000) survey, which sought to explore the issues that school communities considered to result in excused school non-attendance. In the Marsh's study, socio-economic factors, parent-approved absence, history of lack of parental supervision in high school, and household dysfunctionality, concretely contributed to an escalated risk of truancy among college students in Queensland.

The role of family dynamics in truant behaviors is also supported by Sampson and Laub's (1994), an expansion of Hirschi's (1969) social control theory (SCT). The SCT theory considers truancy as a form of delinquency. The extended SCT focuses on three dimensions of the family, namely: attachment, supervision, and discipline (Wagner, Weiss, \& Dunkake, 2004). Notably, the core to all the aforementioned antecedents lies in the degree to which each enables the connection of the student to the household, and consequently, to the society via emotional attachment, supervision, and control (Sampson \& Laub, 1994). The SCT theory posits that poverty and the associated strains arising from economic deficiency undermine parent-child attachments and relationships in the household (Wagner et al., 2004). Therefore, from the interviewees' responses in the current investigation, the effect of economic disempowerment and disadvantaged family status on truancy may be modulated partly by prior lack of parental supervision and discipline practices.

Student interest. In both of the investigated institutions, class attendance is not mandatory; however, students are required to attend at minimum $80 \%$ of classes to qualify to sit for their final exams. Subsequently, the choice to appear for lectures is significantly affected by an array of individual traits that reflect intrinsic inspiration to excel, a heightened degree of self-control, and feeling self-regulation over academic accomplishments. As illustrated by the responses from seven interviewees in the current study, including $\mathrm{P \# 1,P \# 2,} \mathrm{P \# 5,} \mathrm{P \# 6,} \mathrm{P \# 7,} \mathrm{P \# 9,} \mathrm{and} \mathrm{P \# 10,} \mathrm{it} \mathrm{is} \mathrm{clear} \mathrm{that} \mathrm{personality}$ traits play a key role in failing to attend class. For instance, P\#2 and P\#5 indicated that their struggle with classroom difficulties displayed through social isolation, anxiety, self-doubt, and sense of tension that caused them to stay away from school. This is supported by Clores' (2009) outcomes that show that anxiety can be both a cause and an impact of failure in school, as 
apprentices who perform poorly in certain courses can experience apprehension while on the other hand, the low scores can also cause anxiety. Thus, learners lacking grounded coping mechanisms may embrace maladaptive behaviors, including truancy, to tackle failure as in the case of respondents $\mathrm{P} \# 2$ and $\mathrm{P \# 5.}$

A series of the existing literature has also confirmed the association between the decision to be truant to mental disorders that manifest as low selfesteem, substance or alcohol use, social isolation (Skedgell \& Kearney, 2018; van der Woude, van der Stouwe, \& Stams, 2017). As per these scholars, students who score poor results in introductory courses may perceive the entire module as difficult; thus, their likelihood of skipping is high. On the other hand, Dahl (2016) and Heyne, Gren-Landell, Melvin, \& Gentle-Genitty (2018) showed that a significant number of university apprentices skive lectures to party with their friends or use drugs to keep up with peer pressure, aspects that are suggestive of lack of self-control.

Through a quantitative survey, Rijavec and Miljkovic (2015) reported student interest as the most predominant predictor of truancy among $n=258$ campus students sampled from Zagreb University, Croatia. Notably, among the five identified correlates of truancy, including not being in the mood, personal issues, and sickness, and lecture concerns, assiduousness posted the largest effect. The highly hardworking apprentices at Zagreb were less possibly to skive classes compared to their less industrious counterparts. Similarly, Delaney et al. (2013) observed that intellectual qualities, particularly ambitiousness and assiduousness, were significant correlates of class attendance and readiness to actively participate in assignments and school activities. In a study conducted in Austria, Dumfart and Neubauer (2016) found that low levels of shrewdness and conscientiousness alone were ascribed for beyond $40 \%$ of class non-attendance among $n=498$ eighth graders.

West et al. (2016) explored the role of grit, self-control, and conscientiousness in the academic outcomes of $n=1368$ eighth-graders and revealed that all the three antecedents positively shaped lecture turn up rates, students' level of self-regulation and exam performance. In a similar investigation, Hwang, Lim, and Ha (2018) explored the association between grit, conscientiousness, self-control, age, and educational performance among students attending a university in Korea. The upshots illustrated that academic performers were highly likely to be consistent in presenting themselves in lecturers, while less tenacious respondents scored poorly in their exams. The survey outcomes also ascertained that the age of the informants influenced their grades and adaptability to campus practices, while self-efficacy and assiduousness enhanced with the advance in age. 
Hwang et al. (2018) and Dumfart and Neubauer (2016) argue that conscientiousness is an individual trait that ensures that learners adhere to stipulated school rules, norms, and principles, and in turn, embrace goaloriented practices encompassing regular lecture attendance. Cognizant of the above premise, assiduousness is the central element that emasculates the desire to stall, while the associated trait of self-control negatively influences procrastination behaviors. Subsequently, apprentices with heightened levels of self-control are enthused when they have timetabled classes, and they will be committed to attending all classes even when others consider them tedious or boring. Thus, empiricists and policymakers should pay attention to the myriad of individual qualities when formulating and enforcing strategies intended to reduce the high frequencies of truancy among college students in Lebanon.

Instructional modality and lecture content. All the respondents except P\#3 and P\#6 identified the lecturers' teaching modality and the lack of grasped module content as contributors to their truant behaviors. Most of these respondents indicated that they did not see the necessity for attending lessons which had been covered in previous modules, while others felt that since most instructors use PowerPoint presentations (PPT), they preferred acquiring the notes instead of attending highly congested and boring lectures. In a recent investigation, Worthington and Levasseur (2015) evaluated the efficacy of instructor-provided PPTs in enhancing student lecture attendance and recollection of the theoretical principles of the course across two semesters. The study found that availability of PPTs had no significant effect on class attendance, as well as student outcomes, which disapprove the assertions raised by the interviewed response in the present qualitative analysis regarding the perceived effectiveness of PPTs in learning.

\section{Strategies to Reduce Truancy among University Students}

Improvement of teaching strategies. Surprisingly, nearly all of the respondents concurred that the lecturers ought to adjust their teaching approaches to reduce the boredom and disinterest among students. This is evidenced in the available literature, with Desalegn et al.'s (2014) crosssectional investigation proposing regular re-training of professors to improve their approaches when teaching modern students. The training programs will ensure that the lecturers master the course content, inculcate respect among their students, motivate their learners to have a positive attitude towards the module, vary their instructional techniques, employ student-based teaching approach, and transform the classroom into an enlightening and cheerful environment to curb boredom (Desalegn et al. 2014).

Kraft (2017) and Ruzek, Domina, Conley, Duncan, and Karabenick (2015) recommend that professors should engage the students in choosing the 
most preferred instructional modality as exemplified in Alshammari's (2016) research. In the latter investigation, the authors assessed the efficacy of lesson management techniques as a way of tackling truancy in the university and colleges. The upshots highlighted the necessity for collaborative decisionmaking with respect to curbing non-attendance, especially the adoption of class attendance management techniques (CAMTs) and class attendance rules (CAR). The authors submitted that involving learners in decision-making will enhance the adoption and ownership of the stipulated rules, as well improve instructor-student rapport that is essential in both class attendance, positive attitudes towards the modules, and academic performance.

\section{Conclusion}

The purpose of the qualitative investigation was to uncover the nature and causes of truancy among students attending the two Lebanese universities, namely: University of Tripoli and Manar University of Tripoli. The rationale for conducting the research was informed by the aspect that although there are numerous studies which have attributed lecture non-attendance to negative student outcomes, none have been carried out in Lebanon. The exploration adopted a qualitative descriptive framework focusing on the causes and nature of truancy. Ten students from the two selected institutions were chosen as per the maximum variation and criterion sampling techniques. The respondents were engaged in face-to-face interviews, which were taped, coded, and the resulting transcripts were analyzed according to the thematic analytic model. Two themes emerged from the research and four sub-themes. These encompassed the causes of truant behaviors and probable solutions. In the first category, family dynamics, student's personal qualities, including drug use and personality traits, and the teaching methodology and lecturer's mastery of course content were distinguished. In the second theme, only one sub-theme was identified; the need for training professors to facilitate the modification of the classroom to one that supports vibrant interaction among students and between instructors and learners. The investigation entailed an assessment of students who had already failed in the last semester of 2018-2019, which may have limited comparison of responses from those who passed their exams. Besides, the small sample size restricts the generalization of findings, therefore, there is a need for additional studies involving a larger sample to fill the identified gap.

\section{References:}

1. Alshammari, Z. N. (2016). Enhancing higher education student attendance through classroom management. Cogent Education, 41, 112. https://doi.org/10.1080/2331186X.2016.1210488

2. Bati, A. H., Mandiracioglu, A., Orgun, F., \& Govsa, F. (2013). Why 
do students miss lectures? A study of lecture attendance amongst students of health science. Nurse Education Today, 33(6), 596-601. https://doi.org/10.1016/j.nedt.2012.07.010

3. Cantillon, P. (2003). Teaching large groups. British Medical Journal, 326(7386), 437-440. https://doi.org/10.1136/bmj.326.7386.437

4. Clores, M. (2009). A qualitative research study on school absenteeism among college students. The Asia-Pacific Education Researcher, 18(2). https://doi.org/10.3860/taper.v18i2.1320

5. Cortright, R. N., Lujan, H. L., Cox, J. H., \& DiCarlo, S. E. (2011). Does sex (female versus male) influence the impact of class attendance on examination performance? American Journal of Physiology Advances in Physiology Education, 35(4), 416-420. https://doi.org/10.1152/advan.00021.2011

6. Crede, M., Roch, S. G., \& Kieszczynka, U. M. (2010). Class attendance in college: A meta-analytic review of the relationship of class attendance with grades and student characteristics. Review of Educational Research, 80(2), 272-295. https://doi.org/10.3102/0034654310362998

7. Dahl, P. (2016). Factors associated with truancy: Emerging adults' recollections of skipping school. Journal of Adolescent Research, 31(1), 119-138. https://doi.org/10.1177/0743558415587324

8. Delaney, L., Harmon, C., \& Ryan, M. (2013). The role of noncognitive traits in undergraduate study behaviors. Economics of Education Review, 32(1),

$181-195$. https://doi.org/10.1016/j.econedurev.2012.07.009

9. Desalegn, A. A., Berhan, A., \& Berhan, Y. (2014a). Absenteeism among medical and health science undergraduate students at Hawassa University, Ethiopia. BMC Medical Education, 14(1), 1-11. https://doi.org/10.1186/1472-6920-14-81

10. Desalegn, A. A., Berhan, A., \& Berhan, Y. (2014b). Absenteeism among medical and health science undergraduate students at Hawassa University, Ethiopia. BMC Medical Education, 14(1), 1-11. https://doi.org/10.1186/1472-6920-14-81

11. Dey, I. (2018). Class attendance and academic performance: A subgroup analysis. International Review of Economics Education, 28(August 2017), 29-40. https://doi.org/10.1016/j.iree.2018.03.003

12. Draper, A. K. (2005). The principles and application of qualitative research. Proceedings of the Nutrition Society, 63(04), 641-646. https://doi.org/10.1079/pns2004397

13. Dumfart, B., \& Neubauer, A. C. (2016). Conscientiousness is the most powerful noncognitive predictor of school achievement in adolescents. Journal of Individual Differences, 37(1), 8-15. 
https://doi.org/10.1027/1614-0001/a000182

14. Eisen, D. B., Schupp, C. W., Isseroff, R. R., Ibrahimi, O. A., Ledo, L., \& Armstrong, A. W. (2015). Does class attendance matter? Results from a second-year medical school dermatology cohort study. International Journal of Dermatology, 54(7), 807-816. https://doi.org/10.1111/ijd.12816

15. Epstein, J. L., \& Sheldon, S. B. (2002). Present and accounted for: Improving student attendance through family and community involvement. Journal of Educational Research, 95(5), 308-318. https://doi.org/10.1080/00220670209596604

16. Grossoemme, D. (2015). Research methodology/overview of qualitative research. J Health Care Chaplain, 20(3), 109-122. https://doi.org/10.1080/08854726.2014.925660.Research

17. Guleker, R. (2014). The effect of attendance on academic performance. Mediterranean Journal of Social Sciences, 5(23), 961966. https://doi.org/10.5901/mjss.2014.v5n23p961

18. Heyne, D., Gren-Landell, M., Melvin, G., \& Gentle-Genitty, C. (2018). Differentiation between school attendance problems: Why and how? Cognitive and Behavioral Practice. https://doi.org/10.1016/j.cbpra.2018.03.006

19. Hwang, M. H., Lim, H. J., \& Ha, H. S. (2018). Effects of grit on the academic success of adult female students at Korean Open University. Psychological Reports, 121(4), 705-725. https://doi.org/10.1177/0033294117734834

20. Irwin, N., Burnett, K. M., \& McCarron, P. A. (2018). Association between attendance and overall academic performance on a module within a professional pharmacy degree. Currents in Pharmacy Teaching and Learning, 10(3), 396-401. https://doi.org/10.1016/j.cpt1.2017.11.008

21. Jacob, B., \& Lovett, K. (2017, July 27). Chronic absenteeism: An old problem in search of new answers. Brookings. Retrieved from www.brookings.edu/research/chronic-absenteeism-an-old-problemin-search-of-new-answers/

22. Jamshed, S. (2014). Qualitative research method-interviewing and observation. Journal of Basic and Clinical Pharmacy, 5(4), 87-88. https://doi.org/10.4103/0976-0105.141942

23. Jugder, N. (2016). The thematic analysis of interview data: An approach used to examine the influence of the market on curricular provision in Mongolian higher education institutions. Mongolia: National Academy of Governance of Mongolia

24. Kirby, A., \& McElroy, B. (2003). The effect of attendance on grade for first-year economics students in University College Cork. 
Economic and Social Review, 34(3), 311-326.

25. Knoster, K. (2016). Strategies for addressing student and teacher absenteeism: A literature review. Washington, DC: U.S. Department of Education, North Central Comprehensive Center.

26. Kolari, S., Savander-Ranne, C., \& Viskari, E. (2008). Learning needs time and effort: A time-use study of engineering students. European Journal of Engineering Education, 33(5-6), 483-498. https://doi.org/10.1080/03043790802564046

27. Kraft, M. A. (2017). Teacher and teaching effects on students' attitudes and behaviors. Edu Eval Policy Anal, 39(1), 146-170. https://doi.org/10.3102/0162373716670260.Teacher

28. Landin, M., \& Pérez, J. (2015). Class attendance and academic achievement of pharmacy students in a European University. Currents in Pharmacy Teaching and Learning, 7(1), 78-83. https://doi.org/10.1016/j.cpt1.2014.09.013

29. Lukkarinen, A., Koivukangas, P., \& Seppälä, T. (2016). Relationship between class attendance and student performance. Procedia - Social and Behavioral Sciences, 228(June), 341-347. https://doi.org/10.1016/j.sbspro.2016.07.051

30. Marsh, P. (2000). Truancy or absenteeism? A school governance perspective. Queensland Journal of Educational Research, 16(2), 147157. Retrieved from http://www.iier.org.au/qjer/qjer 16/marsh.html

31. Moore, R., Jensen, M., Hatch, J., Duranczyk, I., \& Staats, S. (2003). Showing up: The importance of class attendance for academic success in introductory science courses. The American Biology Teacher, 65(5), 325-329.

32. Nawal, F., Haidar, K., Saad, Z., Hamdar, G., Hujairy, M., A Faris, ... N Ghosn. (2012). Monitoring school absence in the Bekaa governorate -Lebanon. Retrieved August 31, 2019, from https://www.tephinet.org/monitoring-school-absence-in-the-bekaagovernorate-lebanon

33. Palinkas, L. A., Horwitz, S. M., Green, C. A., Wisdom, J. P., Duan, N., \& Hoagwood, K. (2015). Purposeful sampling for qualitative data collection and analysis in mixed method implementation research. Administration and Policy in Mental Health, 42(5), 533-544. https://doi.org/10.1007/s10488-013-0528-y

34. Pengpid, S., \& Peltzer, K. (2017). Prevalence, demographic and psychosocial correlates for school truancy among students aged 13-15 in the Association of Southeast Asian Nations (ASEAN) member states. Journal of Child \& Adolescent Mental Health, 29(3), 197-203. https://doi.org/10.2989/17280583.2017.1377716

35. Pinchak, N. P. (2018). The relationship between teacher regard and 
college attendance expectations: socio-economic and racial-ethnic disparities. Social Psychology of Education, 21(1), 209-221. https://doi.org/10.1007/s11218-017-9396-8

36. Purcell, P. (2007). Engineering student attendance at lectures: Effect on examination performance. Conference on Engineering Education. Retrieved from https://www.researchgate.net/publication/228416978_Engineering_st udent_attendance_at_lectures_Effect_on_examination_performance

37. Rijavec, M., \& Miljkovic, D. (2015). Reasons for missing classes in college: The role of personality traits. Procedia - Social and Behavioral Sciences, 205(May), 480-484. https://doi.org/10.1016/j.sbspro.2015.09.046

38. Ruzek, E. A., Domina, T., Conley, A. M., Duncan, G. J., \& Karabenick, S. A. (2015). Using value-added models to measure teacher effects on students' motivation and achievement. Journal of Early Adolescence, 35(5): 852-882. doi: 10.1177/0272431614525260.

39. Sampson, R., \& Laub, J. (1994). Urban poverty and the family context of delinquency: A new look at structure and process in a classic study. Child Development, 65(2), 523-540.

40. Sekaran, U. \& Bougie, R. 2016. Research methods for business a skillbuilding approach. $7^{\text {th }}$ edn. Chichester, West Sussex, United Kingdom: John Wiley \& Sons, Ltd

41. Skedgell, K., \& Kearney, C. A. (2018). Predictors of school absenteeism severity at multiple levels: A classification and regression tree analysis. Children and Youth Services Review, 86(November 2017), 236-245. https://doi.org/10.1016/j.childyouth.2018.01.043

42. Snyder, J. L., Lee-Partridge, J. E., Jarmoszko, A. T., Petkova, O., \& D'Onofrio, M. J. (2014). What is the influence of a compulsory attendance policy on absenteeism and performance? Journal of Education for $\quad$ Business, 89(8), 433-440. https://doi.org/10.1080/08832323.2014.933155

43. Teixeira, A. A. C. (2016). The impact of class absenteeism on undergraduates' academic performance: evidence from an elite Economics school in Portugal. Innovations in Education and Teaching International, $53(2)$, 230-242. https://doi.org/10.1080/14703297.2014.937730

44. van der Woude, L. B., van der Stouwe, T., \& Stams, G. J. J. M. (2017). Differences between risk factors for truancy and delinquency in Dutch adolescents. Children and Youth Services Review, 73, 9-14. https://doi.org/10.1016/j.childyouth.2016.11.028

45. Wagner, M., Weiss, B., \& Dunkake, I. (2004). Truancy in Germany: A theoretical and empirical analysis. EuroConference on the Causes 
and Consequences of Low Education in Contemporary Europe, Granada, Spain, 18-23.

46. West, M. R., Kraft, M. A., Finn, A. S., Martin, R. E., Duckworth, A. L., Gabrieli, C. F. O., \& Gabrieli, J. D. E. (2016). Promise and paradox: Measuring students non-cognitive skills and the impact of schooling. Educational Evaluation and Policy Analysis, 38(1), 148-170. https://doi.org/10.3102/0162373715597298

47. Worthington, D. L., \& Levasseur, D. G. (2015). To provide or not to provide course PowerPoint slides? The impact of instructor-provided slides on student attendance and performance. Computers and Education, 85, 14-22. https://doi.org/10.1016/j.compedu.2015.02.002 